\title{
PIBID GEOGRAFIA NA ESCOLA ESTADUAL ANTÔNIO PINTO DE MEDEIROS: CONTRIBUIÇÕES PARA UMA FORMAÇÃO CIDADÃ
}

L. R. Miranda'; M. C. C. Araújo'; G. C. de O. Silva; E. J. B. de Oliveira; L. M. S. Lehum; M. V. de Paiva.

'PIBID - Instituto Federal do Rio Grande do Norte

levi.miranda@ifrn.edu.br - cristina.cavalcanti@ifrn.edu.br

Artigo submetido em abril/2012 e aceito em junho/2012

\section{RESUMO}

O presente artigo tem por objetivo divulgar as ações desenvolvidas pelo Programa Institucional de Bolsas de Iniciação a Docência - PIBID - do Instituto Federal de Educação, Ciência e Tecnologia do Rio Grande do Norte - IFRN, mais especificamente as ações do subprojeto de Licenciatura em Geografia na Escola
Estadual Antônio Pinto de Medeiros, localizada no bairro Pitimbú, zona Leste da cidade do Natal/RN, e suas contribuições na promoção da cidadania dos alunos assistidos pelo programa. Realiza, ainda, uma sucinta descrição do PIBID e sua relevância na formação inicial dos licenciandos de Geografia.

PALAVRAS-CHAVE: PIBID; cidadania; formação inicial de professores; ensino.

\section{PIBID GEOGRAPHY IN ESCOLA ESTADUAL PINTO ANTONIO DE MEDEIROS: CONTRIBUTIONS FOR PUBLIC EDUCATION}

\section{ABSTRACT}

This article aims to publicize the actions undertaken by the Institutional Scholarship Program Initiation to Teaching - PIBID - Federal Institute of Education, Science and Technology of Rio Grande do Norte - IFRN, more specifically the actions of the subproject's Degree in Geography in the Escola Estadual
Antonio Pinto de Medeiros, Pitimbu located in the neighborhood, the East of the city of Natal / RN, and his contributions in promoting the citizenship of students assisted by the program. Performs addition, a brief description of PIBID and its relevance in the initial training for future teachers of Geography.

KEY-WORDS: PIBID; citizenship; teacher education; education. 


\section{PIBID GEOGRAFIA NA ESCOLA ESTADUAL ANTÔNIO PINTO DE MEDEIROS: CONTRIBUIÇÕES PARA UMA FORMAÇÃO CIDADÃ}

\section{INTRODUÇÃO}

O contexto atual da escola básica pública no Brasil é marcado pela paulatina defasagem do ensino, salvo raras exceções, como reflexo do descaso dos governantes ao longo dos anos no enfrentamento dos gargalos que emperram o cumprimento do papel social da escola. Desvalorização da carreira docente, baixos investimentos no setor educacional, descontinuidade das políticas educacionais, defasagem da infraestrutura das escolas, são alguns desses gargalos que precisam ser superados. Nessa perspectiva, a busca pela qualidade do ensino, que passa pela formação inicial dos professores, retorna ao centro dos debates e lança novas propostas para a superação do cenário caótico em que se encontra a educação nacional. Dentre essas propostas destaca-se o Programa Nacional de Iniciação à Docência - PIBID, que visa contribuir para a melhoria da educação básica no Brasil a partir da integração entre instituições públicas de ensino superior, que ofereçam cursos de licenciatura, e as escolas da educação básica das redes estadual e municipal de ensino.

Este trabalho discorre sobre o programa supracitado e sua importância para a formação inicial dos estudantes de licenciatura que dele participam. Realiza, ainda, uma breve abordagem das ações desenvolvidas na Escola Estadual Antônio Pinto de Medeiros (EEAPM), no ano de 2011, pelos bolsistas de Licenciatura em Geografia do Instituto Federal de Educação, Ciência e Tecnologia do Rio Grande do Norte - IFRN, cujas atividades têm como norte o desenvolvimento da cidadania dos alunos assistidos pelo PIBID.

\section{PROGRAMA INSTITUCIONAL DE BOLSAS DE INICIAÇÃO À DOCÊNCIA}

Criado pela Coordenação de Aperfeiçoamento de Pessoal de Nível Superior - CAPES, através de sua Portaria Normativa no 122, de 16 de setembro de 2009 (BRASIL, 2009), o Programa Institucional de Bolsas de Iniciação a Docência - PIBID - tem como objetivo principal o apoio à formação de estudantes que optam pela carreira docente a partir do fomento a iniciação à docência.

O Programa efetiva-se por meio do estabelecimento de convênios entre as instituições de educação superior, que forneçam cursos de licenciatura, e as redes de educação básica pública com vistas a promover a atuação dos licenciandos em formação inicial nas práticas pedagógicas dessas escolas. Celebrado o convênio, a CAPES concede bolsas para professores coordenadores, docentes locados na escola de educação básica e os licenciandos selecionados. Os professorescoordenadores correspondem aos docentes ligados às instituições de educação superior e tem como responsabilidade o acompanhamento do planejamento, a organização e a execução das atividades previstas, além do auxílio aos estudantes-bolsistas no suprimento das dificuldades que encontrarem no exercer de suas tarefas. Já o docente em exercício na escola de educação básica, participante do projeto, atua supervisionando as atividades dos bolsistas; ele é a ponte entre a universidade e a escola básica. (BRASIL, 2010). 
O PIBID surge num contexto crítico para educação básica pública nacional em que a desvalorização da carreira docente e os baixos investimentos no setor, ao longo dos anos, geraram um cenário desanimador marcado pela descrença na qualidade do ensino público. As taxas do Índice de Desenvolvimento da Educação Básica (IDEB), indicador que mede a qualidade do ensino das escolas públicas de educação básica no país (relacionando as informações sobre rendimento escolar e desempenho acadêmico), apontam que, em 2009, a média para os anos finais do ensino fundamental e para o ensino médio era de 4,0 e 3,6 respectivamente; pontuações inferiores aos de países desenvolvidos cujo mesmo índice é de 6,0 pontos. No caso do estado do Rio Grande do Norte a situação complica-se ainda mais. Tanto para os anos finais do ensino fundamental quanto para o ensino médio, o estado tem figurado abaixo da média nacional, o que reforça a importância de programas como PIBID.

Porém, chamamos a atenção que o IDEB é uma explicitação clara da adoção de modelos pelo governo nacional no que tange a educação brasileira. Exemplo que mostra a implantação de ideias externas ao contexto local, sem que, geralmente, adaptações sejam realizadas. Portanto, longe da realidade local. Ademais, torna-se compromisso do governo federal que até 2021 Brasil atinja o atual estágio educacional dos países desenvolvidos.

No Rio Grande do Norte o Programa é desenvolvido por quatro instituições de educação superior, a saber: as universidades Federal e Estadual do Rio Grande do Norte - UFRN e UERN respectivamente - a Universidade Federal Rural do Semiárido (UFERSA) e o Instituto Federal de Educação, Ciência e Tecnologia do Rio Grande do Norte (IFRN) (BRASIL, 2011). Neste último, o projeto atual conta a participação de 112 estudantes-bolsistas abrangendo os cursos de licenciatura em Espanhol, Geografia, Física, Matemática e Química (MINISTÉRIO DA EDUCAÇÃO, 2011).

No âmbito do subprojeto da licenciatura em Geografia, o PIBID desenvolve-se em quatro escolas da rede estadual de educação básica: Escola Estadual Professor Castro Alves, Escola Estadual Professor Francisco Ivo Cavalcanti, Escola Estadual Professora Josefa Sampaio e Escola Estadual Professor Antônio Pinto de Medeiros (EEAPM), todas localizadas na cidade do Natal. Intitulado "Por uma leitura geográfica e transformadora de meu lugar-mundo" tem como objetivos: permitir aos estudantes-bolsistas vivenciar a prática docente; oferecer suporte teóricoprático aos professores das escolas públicas em suas atividades pedagógicas; produzir material didático e desenvolver atividades lúdicas de maneira a dinamizar o ensino de Geografia e contribuir para minimização dos problemas de repetência, baixa freqüência escolar e desmotivação; e promover a articulação integrada da Educação Superior do sistema público federal com a Educação Básica do sistema público estadual (RIO GRANDE DO NORTE, 2011).

Com relação ao subprojeto de Geografia na EEAPM, as ações dos bolsistas baseiam-se na busca pelo despertar da cidadania dos estudantes assistidos, pois compartilham da visão de Rego et al (2007, p. 44) de que "a escola deve proporcionar os caminhos necessários para que os sujeitos/alunos possam compreender o cotidiano, desenvolvendo e aplicando competências

\section{CONTRIBUIÇÕES DO PIBID PARA A FORMAÇÃO INICIAL DE PROFESSORES}


Adotando como um de seus objetivos centrais o fomento a formação inicial dos estudantes de licenciatura através de práticas de iniciação à docência, o PIBID adquire fundamental importância no estabelecimento da relação entre teoria e prática.

Cavalcanti (2011) argumenta que frequentemente se relaciona com futuros professores, em período de estágio, tomados por um clima de medo e insegurança em relação ao exercício da profissão. No bojo dessa problemática destacam-se a dificuldade encontrada pelos licenciandos em desenvolver atividades que busquem motivar os alunos e o desafio de fazer com que estes respeitem o professor e contribuam para o bom andamento das aulas. Tal cenário se agrava quando se considera que a prática de estágio, geralmente, ocorre nos anos finais dos cursos de formação de professores. De uma hora para outra, os licenciandos deparam-se com uma realidade pouco vivenciada, durante sua trajetória no curso superior; muitos se espantam chegando até mesmo a desistir da carreira.

Conhecer a realidade, o cotidiano da escola pública é fundamental para o desenvolvimento de práticas educacionais voltadas para uma aprendizagem significativa. Como nos lembra Passini et al (2011, p. 69): "Para fazermos uma proposta de escola viva, organizada para o aluno estudar, nós, como educadores, devemos conhecer sua realidade e os anseios dos alunos".

Nessa perspectiva o PIBID, ao permitir o contato com a realidade da escola básica pública já nos momentos iniciais do curso de licenciatura, antevendo experiências e reflexões que comumente só ocorreriam nas etapas finais deste, contribui para minimizar as incertezas dos estudantesbolsistas com relação à tarefa de educar, possibilitando aos mesmos não iniciar na profissão totalmente imaturos e/ou alienados da realidade do ensino básico do Brasil.

\section{ENSINO DE GEOGRAFIA PARA O EXERCÍCIO DA CIDADANIA}

A sociedade do mundo atual caracteriza-se por constantes e rápidas modificações que exigem uma postura diferenciada da escola no que diz respeito aos métodos de ensino empregados. Já não se pode conceber que os indivíduos que frequentem esta instituição continuem a ser meros espectadores do processo de aprendizagem.

Apesar dos avanços nas teorias de aprendizagem e na própria sociedade de modo geral, constata-se que prevalece, ainda, na escola pública brasileira um ensino calcado na assimilação acrítica, na memorização/repetição dos conhecimentos. $O$ descompasso entre as exigências do mundo contemporâneo e o ensino ofertado põe na ordem do dia a superação dos métodos tradicionais de ensino. A esse respeito Martins (2011, p. 66) esclarece que,

Falar do papel da escola hoje implica destacar as mudanças da sociedade ligadas às transformações e os avanços tecnológicos, científicos e nos meios de comunicação que influenciaram no mercado de trabalho, impulsionando o processo de qualificação profissional. Essa nova realidade exige que a escola repense seu papel e sua organização.

Em se tratando do ensino de Geografia a superação dos métodos supracitados é fundamental para que os estudantes percebam a importância desse conhecimento para compreender os fenômenos geográficos no contexto do mundo globalizado atual. $O$ ensino dessa 
ciência deve permitir ao aluno descobrir o mundo em que vive atentando para uma abordagem crítica das questões ambientais e as relações sociedade/natureza, realizar estudos do meio a fim de que o conteúdo ensinado não se restrinja ao teórico, mas abarque o real, o cotidiano das pessoas (MARTINS, 2011apud VESENTINI, 1996).

Muito mais do que saber a capital dos estados brasileiros a geografia escolar têm de ser ferramenta para que os estudantes intervenham na realidade, exercitando a sua cidadania. Recorremos novamente a Martins (2011, p. 65 apud VESENTINI, 1992) para afirmar que o ensino da Geografia precisa ser desenvolvido de forma que o educando possa

se libertar das amarras da dependência intelectual e de pensamento, encontrar a sua criatividade e imaginação, aprender a pensar a partir do diálogo com o real e com as obras culturais, se descobrir como cidadão e, consequentemente, agente de mudanças (grifos nossos).

É com esta perspectiva que as ações do PIBID na EEAPM estão sendo desenvolvidas. Assim, cabe demonstrar aqui algumas dessas ações que, a nosso ver, tem contribuído para o despertar da cidadania dos estudantes atendidos pelo Programa.

\section{AÇÕES DESENVOLVIDAS}

\section{Reuniões de planejamento}

Finalizado o processo de seleção dos bolsistas do PIBID, iniciou-se um ciclo de reuniões e seminários que tinham por objetivo a apresentação do programa e a supressão das dúvidas quanto às atividades a serem desenvolvidas nas escolas participantes do projeto. Os seminários constituem-se desde o início como um espaço de socialização das atividades e diálogo permanente com os coordenadores. Permite a análise constante das ações a serem desenvolvidas e consequentemente do próprio trabalho dos bolsistas. Como bem aponta Freire (1996, p. 22) "a reflexão crítica sobre a prática se torna uma exigência da relação Teoria/Prática sem a qual a teoria pode ir virando blá-blá-blá e a prática, ativismo".

\section{Observação de aulas}

Este acompanhamento (ver figura 01) buscou levantar junto aos alunos da escola os anseios deles com relação ao ensino de Geografia; quais as dificuldades enfrentadas no processo de aprendizagem, quais técnicas poderiam proporcionar um melhor rendimento escolar etc. Possibilitou um melhor direcionamento das atividades dos bolsistas, uma vez que, ao conhecer o aluno, suas possibilidades e limitações, é possível criar abordagens mais adequadas a sua realidade. 


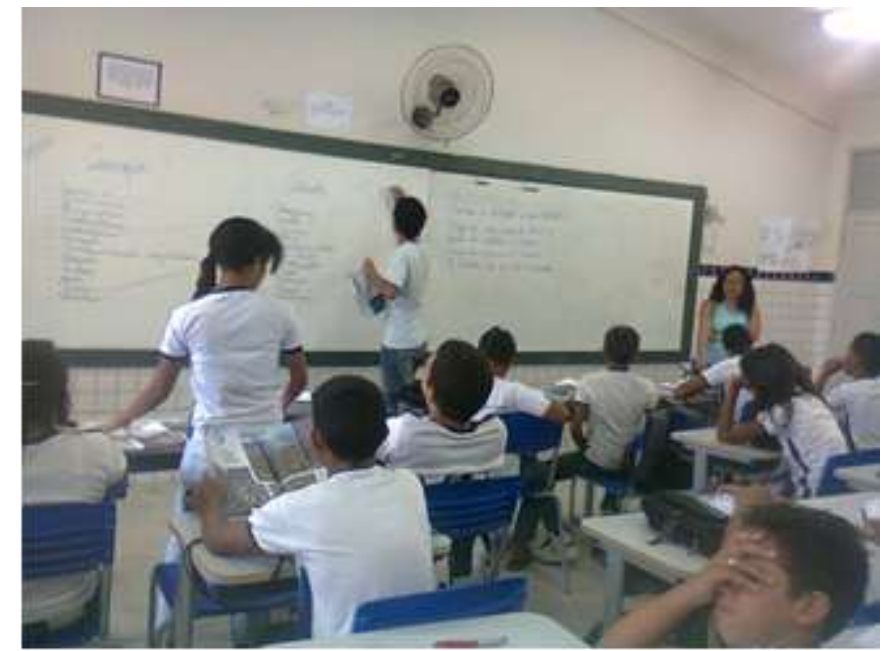

Figura 1 - Observação de aulas

Fonte: acervo dos autores, 2011.

\section{Estudo do meio}

Mediante a discussão sobre a preservação do meio ambiente na academia e nas diversas esferas da sociedade, optou-se que as ações desenvolvidas na escola fossem permeadas por essa temática, a fim de que os alunos envolvidos diretamente no projeto, o corpo escolar e os próprios bolsistas desenvolvessem reflexões acerca dessa problemática.

Com esse objetivo foi realizado um estudo do meio (ver figura 02) no espaço interno da escola e nos seus arredores com estudantes dos 60 ano. A ação contemplou, ainda, a exibição de um vídeo que analisava a relação entre a dinâmica social e os problemas ambientais. A intenção era promover o entendimento de que o espaço geográfico é constituído a partir da interação entre sociedade e natureza.

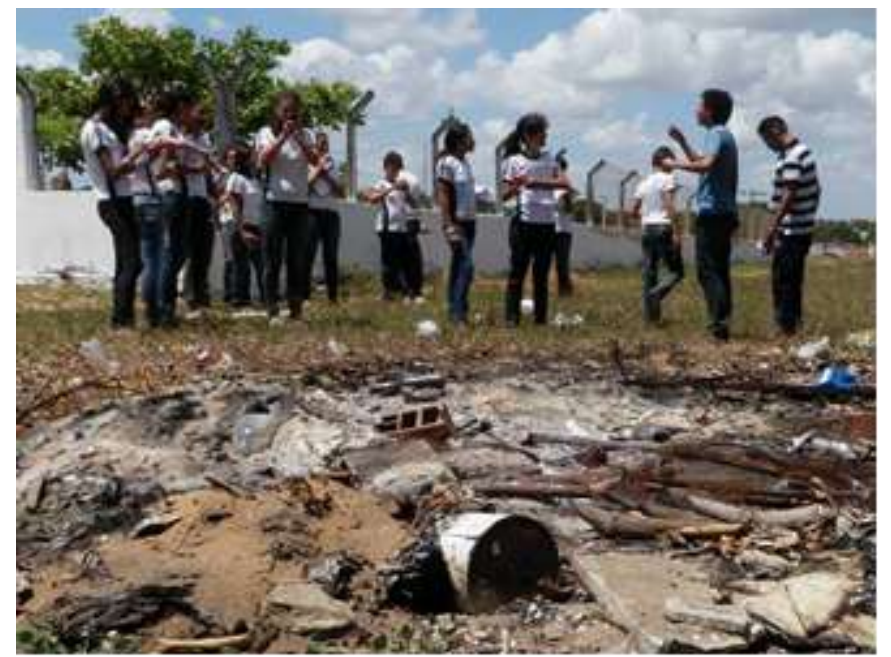

Figura 2 - Estudo do meio realizado no entorno da escola Fonte: acervo dos autores, 2011.

\section{Oficinas}

Dentre as oficinas realizadas destaca-se a da estrutura interna da terra. Pensada com o objetivo de tratar de maneira mais lúdica o conteúdo supracitado, constitui-se na exibição de 
vídeos que versavam sobre a formação do Planeta Terra e na construção de globos terrestres compartimentados em camadas que representassem a estrutura estratificada do Planeta (ver figura 03, 04 e 05).

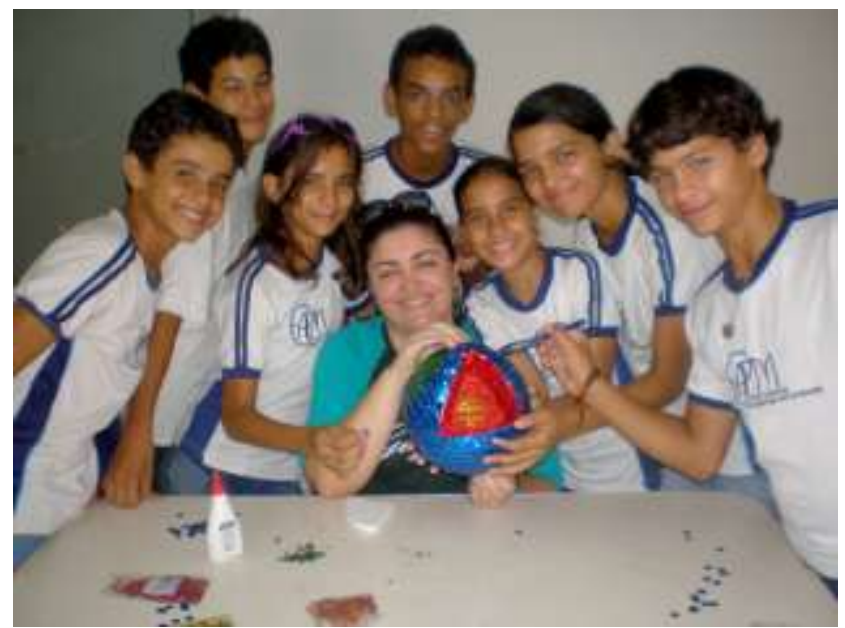

Figura 3 - Oficina de construção da estrutura interna da Terra Fonte: acervo dos autores, 2011.

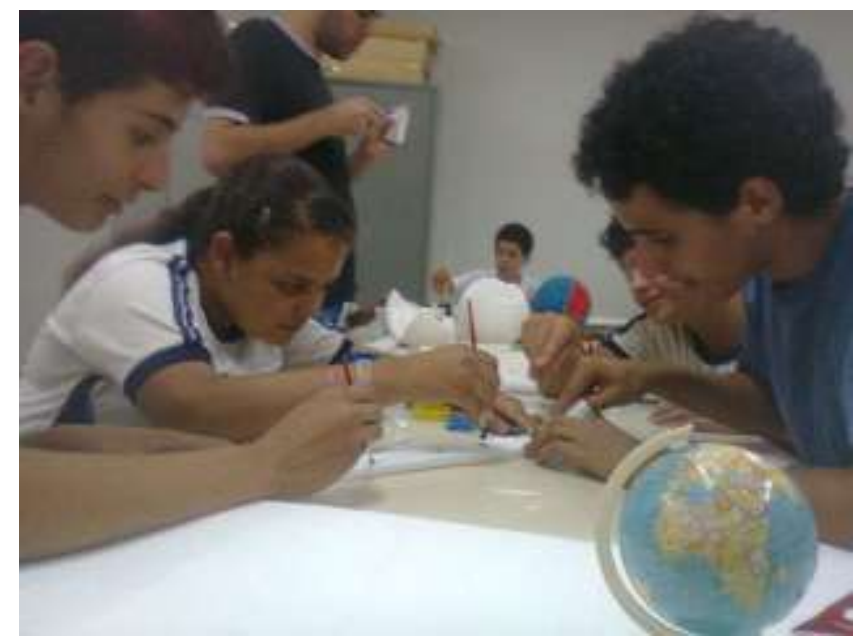

Figura 4 - Alunos construindo globos terrestres Fonte: acervo dos autores, 2011. 


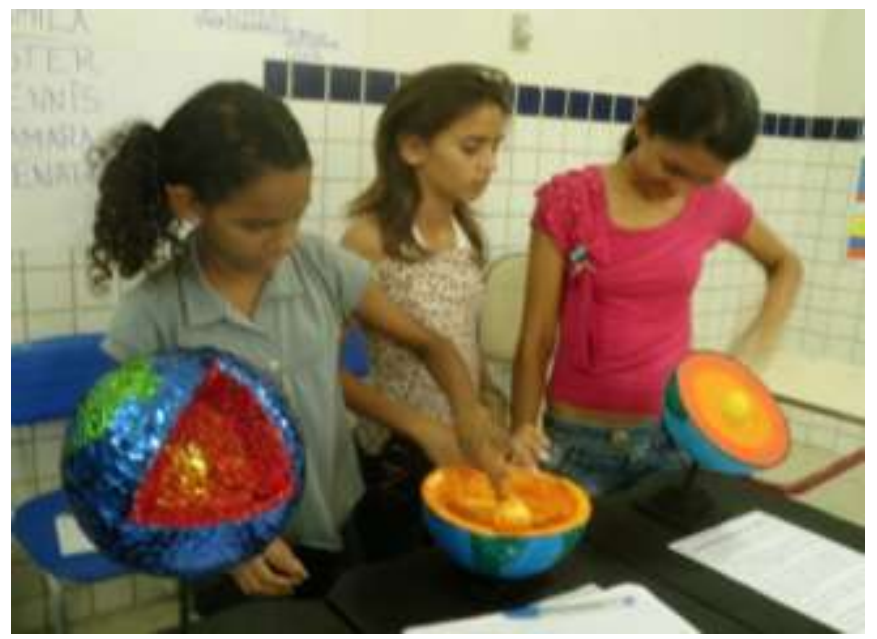

Figura 5 - Alunos usando o material produzido nas aulas de Geografia Fonte: acervo dos autores, 2011.

Interessante destacar aqui é o fato de que os globos produzidos pelos estudantes serviram como material didático para as aulas dos professores de Geografia da EEAPM. Assim, ao invés de levarmos um material pronto, possibilitou-se que os próprios alunos o construíssem.

\section{FUTURAS AÇÕES}

Considerando o êxito das ações desenvolvidas no ano de 2011 na escola conveniada, pretende-se essas manter e inserir outros projetos no início deste ano de 2012. Dentre eles destacam-se a realização de oficinas de cartografia por meio das quais os estudantes irão adquirir noções básicas de localização espacial e compreensão de mapas; mostras culturais e cinematográficas; organização/elaboração de material didático para auxílio nas práticas dos professores de Geografia da escola; reforço escolar e aulões de apoio aos estudantes que irão prestar vestibular.

\section{CONCLUSÃO}

Conclui-se, a partir das experiências vivenciadas durante o ano de 2011, que ações pensadas e voltadas para a melhoria da educação devem priorizar a formação inicial e continuada de professores. Nesse contexto, programas que permitam o intercâmbio entre a universidade e a escola básica, como é o caso do PIBID, são fundamentais para assegurar a qualidade do processo pedagógico.

Apesar das dificuldades encontradas nos momentos iniciais do desenvolvimento do PIBID, os bolsistas vêm conseguindo promover ações de melhoria do ensino. Percebeu-se, no próprio relato de professores, a mudança de comportamento de alguns estudantes que antes demonstravam desinteresse, desânimo com o ensino de Geografia e depois de algumas intervenções dos bolsistas passaram a adotar uma postura mais ativa nas tarefas escolares. 


\section{REFERÊNCIAS BIBLIOGRÁFICAS}

1. BRASIL. MINISTÉRIO DA EDUCAÇÃO E CULTURA. Portaria Normativa da CAPES no 122, de 16 de setembro de 2009. Cria o Programa Institucional de Bolsa de Iniciação à Docência (PIBID). Brasília, 2009.

2. Edital CAPES no 01/2011 Relação de projetos aprovados. Diário Oficial da União, Brasília, 07 abr. 2011. Disponível em: http://www.capes.gov.br/images/stories/download/editais/resultados/Resultado-Pibid-DOU7-4-2011.pdf. Acesso em: 23 mar. 2012.

3. BRASIL. Decreto no 7.219, de 24 de junho de 2010. Dispõe sobre o Programa Institucional de Bolsas de Iniciação à Docência - PIBID e da outras providências. Diário Oficial da União, Brasília, 25 jun. 2010. Disponível em http://www.capes.gov.br/images/stories/download/diversos/DecretoPIBID_240610.pdf. Acesso em: 23 mar. 2012.

4. CAVALCANTI, L. S. A geografia escolar e a sociedade brasileira contemporânea. In: TONINI, Ivaine Maria et al (orgs). $\mathbf{O}$ ensino de Geografia e suas composições curriculares. Porto Alegre: UFRGS, 2011.

5. FREIRE, Paulo. Pedagogia da autonomia: saberes necessários à prática educativa. 42. ed. São Paulo: Paz e Terra, 1996.

6. MARTINS, R. E. M. W. A trajetória da Geografia e seu ensino no século XXI. In: TONINI, Ivaine Maria et al (orgs). $\mathbf{O}$ ensino de Geografia e suas composições curriculares. Porto Alegre: UFRGS, 2011.

7. MINISTÉRIO DA EDUCAÇÃO. INSTITUTO FEDERAL DE EDUCAÇÃO, CIÊNCIA E TECNOLOGIA DO RIO GRANDE DO NORTE. Edital no 05/2011. Seleção de bolsistas de iniciação à docência dos cursos de licenciaturas participantes do PIBID - programa institucional de bolsas de iniciação à docência - edital MEC/CAPES 01/2011. Disponível em: http://portal.ifrn.edu.br/pesquisa/editais/editais-2011/EDITAL\%2005\%20PIBID\%20IFRNCAPES.pdf/view. Acesso em: 23 mar. 2012.

8. PASSINI, Elza Yasuko; PASSINI, Romão; MALYSZ, Sandra T. Prática de ensino de Geografia e estágio supervisionado. 2. ed. São Paulo: Contexto, 2011.

9. REGO, Nelson; CASTROGIOVANI, Antonio Carlos; KAERCHER André. Geografia. Porto Alegre: Artmed, 2007.

10. RIO GRANDE DO NORTE. Instituto Federal de Educação, Ciência e Tecnologia do. Programa Institucional de Bolsa de Iniciação à Docência - PIBID : detalhamento do SUBPROJETO (Licenciatura em Geografia) / Levi Rodrigues de Miranda (coordenador). Natal: CAPES / IFRN, (2011). 